Running head: EMOTIONAL COMPLEXITY AND DEHUMANIZATION

\title{
Perceiving Mixed Valence Emotions Reduces Intergroup Dehumanization
}

Francesca Prati ${ }^{1}$ and Roger Giner-Sorolla ${ }^{2}$

Final accepted version, Cognition and Emotion

${ }^{1}$ Department of Psychology, University of Bologna, Italy

Postal address: 5, Berti Pichat, Bologna, 40126, Italy

Telephone number: (+39)0512091885

Email: francesca.prati@unibo.it

${ }^{2}$ Centre for the Study of Group Processes, University of Kent, UK

Postal address: Canterbury, Kent CT2 7NP, United Kingdom

Telephone number: $+44(0) 1227823085$

Email: r.s.giner-sorolla@kent.ac.uk

Word Count: 7944

\section{Author note}

Correspondence regarding this article should be sent to Francesca Prati at the Department of Psychology, University of Bologna, Italy, email: francesca.prati@unibo.it 
Perceiving Mixed Valence Emotions Reduces Intergroup Dehumanization

\begin{abstract}
To deny others' humanity is one of the most heinous forms of intergroup prejudice. Given evidence that perceiving various forms of complexity in outgroup members reduces intergroup prejudice, we investigated across three experiments whether the novel dimension of emotional complexity, or outgroup members' joint experience of mixed-valence emotions, would also reduce their dehumanization. Experiment 1 found that perceiving fictitious aliens' experience of the same primary emotions (e.g., sadness) presented in mixed vs. non-mixed valence pairs led to reduced prejudice via attenuated dehumanization, i.e. attribution of uniquely human emotions.

Experiment 2 confirmed these results, using an unfamiliar real-world group as an outgroup target. Experiment 3 used a familiar outgroup and found generally similar effects, reducing social distance through reduced dehumanization. These processes suggest that an alternate route to reduced dehumanizing of outgroups might involve presenting mixed valence emotions.
\end{abstract}

(Words Count: 137)

Keywords: Emotions, Dehumanization, Intergroup Relations, Intergroup Bias, Social Distance 
Perceiving Mixed Valence Emotions Reduces Intergroup Dehumanization

When war propaganda paints pictures of the enemy as beasts or machines; when euphemisms reduce human lives lost in war to "soft targets" or "collateral damage"; when another culture is characterized as incapable of feeling uniquely human emotions such as guilt or shame; the process of dehumanization is at work. The link between dehumanization and negative treatment of others has been remarked upon in the context of intergroup violence and aggression. By denying their humanity, people remove outgroups from their circle of moral concern, facilitating not just derogation but direct aggression at the intergroup level (Bar-Tal, 1990; Kelman, 1973; Opotow, 1990; Staub, 1989) and interpersonal level (Greitemeyer \& McLatchie, 2011). This helps to facilitate and justify direct violence exerted towards outgroup members (e.g., Castano \& Giner-Sorolla, 2006; Čehajić, Brown, \& González, 2009).

A particular form of intergroup dehumanization has been investigated, under the labels of “infrahumanization" (Leyens et al., 2000, 2001) or "human-uniqueness dehumanization" (Haslam, 2006). Infrahumanization describes the tendency to attribute less uniquely human characteristics (e.g., sophisticated emotional repertoire, intellectual abilities) to outgroup members compared to ingroup members. This has been demonstrated in studies directly assessing attributions of uniquely human traits (for a review, see Haslam \& Loughnan, 2014). It is also shown in numerous studies wherein the outgroup, relative to the ingroup, is attributed a lower capacity to feel secondary or uniquely human (UH) emotions such as shame, nostalgia, or hope, compared to primary or non-uniquely human $(\mathrm{N}-\mathrm{UH})$ emotions which are believed to be shared with other animals, such as anger, fear, or pleasure (for reviews, see Demoulin, Rodríguez, et al., 2004; Vaes, Leyens, Paladino, \& Miranda, 2012). These two measures of infrahumanization - the attribution of UH traits and the capacity to feel UH emotions - in turn relate to direct metaphorical exclusion of their targets from the human category (Loughnan, Haslam, \& Kashima, 2009). 
UH emotions stand out as uniquely human in part because they are seen as cognitively complex (Demoulin et al., 2004). They often depend on keeping in mind a view of the self, the past or the future, whereas $\mathrm{N}-\mathrm{UH}$ emotions react to immediate things in the environment. Moreover, people with intellectual disabilities are seen as less capable of feeling UH emotions than are people with physical disabilities (Chisango, 2012). However, it is possible that uniquely human emotional experience can at the same time arise from a different, unexamined kind of complexity: when a person feels multiple $\mathrm{N}-\mathrm{UH}$ emotions with mixed affective valence in reaction to the same event.

Mixed valence emotions themselves are a thriving topic of research, addressing such questions as whether two emotions can actually be felt at the same time (Larsen \& McGraw, 2014), and what outcomes such experiences have for well-being (Hershfield, Scheibe, Sims, \& Carstensen, 2013). More relevant to our question, research on children shows that, as with UH emotions, both the understanding and experience of mixed valence emotional experiences develop relatively late (Larsen, To \& Fireman, 2007). Also, cognitive reminders of a wider construal for events, such as a joyous event that is the last of its kind, also tend to produce mixed valence emotions (Ersner-Hershfield, Mikels, Sullivan, \& Carstensen, 2008). These examples suggest that the ability to feel emotions of different valences toward the same event may be taken as evidence of more advanced, abstract cognitive capacities. However, to our knowledge, no research has looked at the unitary versus mixed nature of perceived emotions as an indicator of human uniqueness, or as an element of intergroup bias.

We propose that mixed states of two or more opposite valence emotions, felt simultaneously or in close succession, also can serve as an indicator of human uniqueness and human status, even when the emotions in question are themselves $\mathrm{N}-\mathrm{UH}$ emotions. We tested this hypothesis in three studies with outgroup targets, presenting all participants with the same four 
$\mathrm{N}$-UH emotions attributed to the target group, and varying only whether they were described as occurring in mixed-valence or same-valence pairs.

In addition to showing how human uniqueness can be inferred from mixed emotional experience, this method also rules out the alternative explanation that humanity inferences depend only on the number of distinct emotions described. Valence is consistently found to be the most important semantic dimension in the understanding of emotions (e.g., Fontaine, Scherer, Roesch, \& Ellsworth, 2007; Romney, Moore, \& Rusch, 1997; Shaver, Schwartz, Kirson, \& O'Connor, 1987), and indeed most studies and reviews of mixed emotions define this construct as involving mixed-valence pairs (rather than, say, same-valence mixtures of anger and disgust, or of joy and pride; Larsen \& McGraw, 2014). Therefore, we expected greater attributions of UH characteristics to those expressing two emotions of opposite valence in response to a single event, than to those expressing two different emotions of the same valence.

Our research plan also tackled a causal question of immediate relevance to improving intergroup relations: whether describing mixed N-UH emotions among members of another group could improve general attitudes toward them. Merely describing outgroup members as expressing UH emotions is apparently not a sure road to acceptance. While a few studies find positive effects on helping (e.g., Cuddy, Rock, \& Norton, 2007), many others find that expressions of UH emotions from outgroups do not improve attitudes, are not believed or recognized, and sometimes elicit negative reactions (for a review see Vaes, Leyens, Paladino, \& Miranda, 2012). For example, Wohl, Hornsey and Bennett (2012) found that outgroup members apologizing by expressing UH emotions, such as remorse, were believed less than outgroup members who expressed N-UH emotions in their apology, such as sadness. Given the evidence that N-UH emotions are seen as most appropriate to an outgroup, we wondered if they could still indicate a greater degree of complexity and humanity by being presented as mixed emotions, and thus reduce prejudice. 
Increasing the ecological validity of our target groups in line with precedent in the literature (e.g., Castano \& Giner-Sorolla, 2006), we started with a hypothetical sentient species (Experiment 1), then moved to an unfamiliar outgroup (Experiment 2), and finally a familiar but disliked outgroup (Experiment 3). Although we always measured attribution of the capacity to feel UH emotions as an index of humanization, the studies also included varied alternative measures of humanity such as traits or category adjectives, and varied measures of prejudice such as direct group attitudes and social distance.

\section{Experiment 1}

Experiment 1 provided a first test of the notion that perceiving others' complexity through the expression of their mixed valence emotions may promote seeing them as having uniquely human qualities. Specifically, we expected that perceiving mixed valence N-UH emotions vs. same valence $\mathrm{N}-\mathrm{UH}$ emotions experienced by fictitious group members would lead to greater attribution of UH traits and emotions to the target group in question. We also tested whether UH emotions and traits would mediate the relationship between manipulation of fictitious group members' increased emotion complexity and reduced prejudice toward them.

\section{Method}

\section{Participants and Research Design}

Sixty-seven students (53 females, 13 males, and one who did not indicate gender, $M_{\text {age }}=$ $20.48, S D=3.34$ ) at a British university who participated on a voluntary basis were randomly assigned to one of two conditions each with two sub-conditions: mixed emotions (positive first vs. negative first), and same valence emotions (positive emotions first, negative emotions first). However, our key hypothesis-supporting analysis focused on the a priori contrast between mixed and non-mixed or same emotions conditions, effectively creating a two-level design. This design was admittedly optimistic in its sampling, having $80 \%$ power to detect a medium to large effect ( $d$ 
$=.70)$; the research was conducted before Simmons, Nelson and Simonsohn $(2011 ; 2017)$ revised their $\mathrm{N}=20$ recommendation for sample size, and we thought a minimum of 30 per group for the key test would be adequate for our purposes. To look for challenges to the generalization of our findings, we also conducted secondary analyses comparing the two mixed emotions versions to each other, and the positive-only condition to the negative-only condition.

\section{Procedure and Measures}

Participants were first asked to read the following cover story on fictitious group members.

"In the year 2099 during a space expedition humans have their first contact with other creatures on the planet called Ananke. In the first few moments of their approach humans and creatures stand one in front of the other and try to communicate on the basis of facial expressions. During this unusual conversation, creatures express specific emotions." In the positive-first same-valence emotions condition, the creatures expressed first "joy and pleasure" and then "anxiety and fear", in the negative-first same- valence condition they expressed first "anxiety and fear" and then "joy and pleasure", while in the two mixed-valence emotions conditions they expressed first "joy and fear" (or "anxiety and pleasure") and then "anxiety and pleasure" (or "joy and fear").

After reading the cover story, participants were asked to complete a paper-and-pencil questionnaire containing the dependent variables. Then, they were thanked and debriefed.

\section{Dependent Variables}

UH emotions. In this study, because we manipulated the nature of N-UH emotions attributed to the fictitious group, we thought it adequate to focus our measure of emotional attribution only on the attribution of UH emotions. Participants were asked to rate how much they thought the creatures possessed the ability to experience eight different emotions on a scale relative to the human population; from 1 (much less than the average population) to 7 (much 
more than the average population), with 4 described as meaning that the target possesses the ability "neither less nor more than the average population". These emotional experiences consisted of four positive (compassion, admiration, optimism, pride) and four negative (remorse, envious, melancholy, regret) UH emotions. Emotional terms representing each category were chosen from Demoulin et al. (2004).

Ratings were then averaged into a mean score of UH emotions $(\alpha=.64)$.

Human traits. A list of 27 traits was taken from previous studies in which normative data on the human nature, human uniqueness, and desirability of many traits were available (Haslam \& Bain, 2007). Participants first rated how much the creatures they had just read about possessed each trait compared to the average human population. Each trait was rated from 1 (much less than the average population) to 7 (much more than the average population), with the midpoint of 4 described as "neither less nor more than the average population" (see also Prati, Vasiljevic, Crisp \& Rubini, 2015). On the basis of Haslam (2006) categorization, traits were averaged into two distinct scales: ten human nature (HN; curious, sociable, defensive, hedonistic, selfish, active, conforming, nervous, instinctive, uncooperative; $\alpha=.61$ ) and ten uniquely human (UH; optimistic, broadminded, trusting, humble, talkative, conventional, insecure, irresponsible, negligent, arrogant; $\alpha=.71$ ), with seven filler traits that did not fit either category.

Mental experience. Six additional trait items measured general attribution of mental experience of the creatures (thinking, intending, imagining, wishing, seeing, tasting, hearing; $\alpha=$ .56). They were averaged into a mental experience 4-item scale, discarding the two items with lowest item-total correlations (thinking, intending, imagining, wishing; $\alpha=.61$ ), with the caveat that these still showed low reliability.

Prejudice. At the end of the questionnaire, participants were presented six pairs of bipolar adjectives with which to express their own feelings or emotional states (i.e., cold-warm, positive- 
negative, friendly-hostile, suspicious-trusting, respectful-contempt, admiration-disgust) toward the creatures on 7-point Likert scales. These anchors were chosen from Wright, Aron, McLaughlinVolpe \& Tropp's (1997) measure. This intergroup prejudice scale had good internal reliability with a Cronbach's alpha of .73 .

We report all measures used, all manipulations, and all exclusions in our three studies; sample size was always finalized before data analysis. Moreover, this study and the following ones represent the only tests of the hypothesis conducted by the researchers to date.

\section{Results}

To test the hypothesis of differences between mixed and same valence emotions, t-tests comparing the two main levels of the emotional complexity manipulation (same vs. mixed valence) were conducted, and followed up by t-tests within each level comparing the two different versions that varied the order of presentation. Table 1 gives correlations between all variables, and means and SD for the mixed and same valence conditions separately.

\section{UH Emotions}

Describing the creatures as having mixed valence emotions, compared to same valence emotions, increased views of their ability to express UH emotions, $t(65)=-2.17, p=.033, d=.54$ (see Table 1). Nested effects of positive- vs. negative-first unmixed emotions, $t(30)=0.82, p=$ $.418, d=.29$, and of the different mixed emotions conditions, $t(33)=0.15, p=.879, d=.06$, were not significant.

\section{Human Traits}

UH traits. Describing the creatures as having mixed valence emotions led to attributing higher scores of UH traits to them compared to same valence emotions, $t(65)=-3.03, p=.003, d=$ .75. The nested effect of order within the mixed emotion condition was not significant, $t(33)=$ $0.82, p=.737, d=.12$, but there was an unexpected nested effect of valence order within the non- 
mixed condition, $t(30)=2.13, p=.041, d=-.80$. Creatures were seen as having more UH traits when the negative emotions came first than when they came second.

HN traits. For HN traits, there was no significant difference between same- and mixedvalence conditions, $t(65)=-1.22, p=.228, d=.23$. Nested effects of positive- vs. negative-first unmixed emotions $t(30)=-1.12, p=.269, d=-.39$ and those of mixed emotions conditions $t(33)=$ $0.44, p=.663, d=.16$ were not significant.

To compare UH and HN traits directly, a 2 (emotional complexity: same, mixed valence emotions) $\times 2$ (human traits: $U H, H N$ ) mixed model ANOVA with repeated measures on the last factor was conducted on the two types of human traits scores. This showed a significant emotional complexity effect, $F(1,65)=5.76, p=.014, \eta^{2}=.08$, which was modified by an Emotional Complexity $\times$ Human Traits interaction, $F(1,65)=5.34, p=.018, \eta^{2}=.08$. Thus, the difference in effects of the emotional complexity manipulation between the two types of traits was itself significant.

Mental experience. The manipulation of emotional complexity had only a marginally significant effect on mental experience judgments (same $M=4.15, S D=0.82$; mixed $M=4.47, S D$ $=0.59), t(65)=-1.86, p=.067, d=.46$. Nested effects of positive- vs. negative-first unmixed emotions $t(30)=-1.02, p=.314, d=.36$ and those of mixed emotions conditions $t(33)=0.183, p=$ $.856, d=.05$ were not significant.

\section{Prejudice}

A significant effect of the creatures' emotion complexity on prejudice towards them was found. The mixed valence condition elicited less prejudice (i.e., greater liking) towards creatures than did the same valence condition, $t(65)=3.08, p=.003, d=.98$. Nested effects between positive- vs. negative-first same emotions, $t(29)=0.90, p=.929, d=.03$, and between mixed emotions conditions, $t(33)=0.18, p=.855, d=.07$, were not significant. 


\section{Mediation}

Finally, we examined the mediating role of UH emotions and UH traits in the relationship between manipulation of creatures' emotion complexity and prejudice toward them (see Figure 1). We used a bootstrapping mediation analysis with 5,000 re-samples to construct asymmetrical, bias corrected, accelerated 95\% confidence intervals (Preacher \& Hayes, 2008) around the standardized indirect effect of emotional complexity, via the simultaneous mediators of UH emotions and UH traits, on intergroup prejudice. In this analysis, a confidence interval that does not contain zero is equivalent to evidence for mediation at $p<.05$. Overall, $\mathrm{UH}$ emotions $(\mathrm{B}=-.10$, $\mathrm{SE}=.07,95 \% \mathrm{Cl}=-.34$ to -.008$)$ but not $\mathrm{UH}$ traits $(\mathrm{B}=-.07, \mathrm{SE}=.08,95 \% \mathrm{Cl}=-.29$ to .04$)$ significantly mediated emotional complexity effects on intergroup prejudice.

\section{Discussion}

Experiment 1 supported the hypothesis that perceiving outgroup members' expression of mixed valence emotions promotes their humanization, in terms of enhanced attribution of UH emotions and UH traits. Importantly, expressing mixed valence increased all evaluations of the target creatures, as shown by the lack of effect on HN traits, which - in an interaction analysis was different from the effect on UH traits. We also showed that the manipulation of emotional complexity reduced prejudice toward this novel group and this effect was explained by the attribution of UH emotions, but not by the attribution of UH traits.

\section{Experiment 2}

In Experiment 2 we tested whether Experiment 1's results could be extended to a real but little-known outgroup, namely Uzbeks (for British participants). We hypothesized again that perceiving mixed vs. same valence N-UH emotions experienced by Uzbeks would promote their perceived humanization, through increased attribution of the ability to express UH emotions. 


\section{Participants and Research Design}

Seventy-nine adults ( 46 females and 33 males, $M_{a g e}=24,86, S D=3.83$ ) at a British university participated in the experiment on a voluntary basis. The design was the same as in Experiment 1. Based on the medium to large effect sizes of $d=.5$ to $d=.9$ observed in the previous study, we thought the sample size, with $80 \%$ power to detect $d=.64$ in a two-group comparison, was reasonable.

\section{Procedure and Measures}

Participants were asked to read the following cover story on Uzbeks and then answer some questions on their impression about them.

Uzbeks are Central Asia's largest population group. Although they make up over $4 \%$ of the world's population, very little is known about them among people in the West. In order to increase knowledge about this population, BBC interviewers went to Uzbekistan and spent several days getting to know a village of traditional Uzbeks, in the Namangan province to the east of the capital Tashkent. The interviewers remarked on the changing emotional tone as they got to know the villagers.

At first these rural Uzbeks expressed [specific emotions]. In interviews with British embassy personnel, long-time residents of the country confirmed that this pattern of emotions is typical of traditional Uzbeks living in the country. These observations were also confirmed by Peter Cederstav, an anthropologist from the University of Indiana who has spent time studying the Uzbeks of Namangan.

In the positive same valence emotions condition Uzbeks' specific emotions were described as "a mixture of happiness and pleasure; then over time, these emotions changed, to fear mixed with anger"; in the negative same valence condition they expressed first "a mixture of anger and 
fear; then over time, these emotions changed, happiness mixed with pleasure". In the two mixed valence emotions conditions they expressed first "a mixture of anger and pleasure; then over time, these emotions changed, to fear mixed with happiness" or first "a mixture of happiness and fear; then over time, these emotions changed, to anger mixed with pleasure." After that, participants were asked to complete dependent variables and demographic measures, then were thanked and debriefed.

\section{Dependent Variables}

We asked participants to indicate to what extent they thought Uzbeks were able to express six UH emotions (compassion, admiration, optimism, remorse, envy, melancholy; $\alpha=.69$ ) compared to the average human population, as in Experiment $1^{1}$. This time, in order to be able to compare uniquely human to non-uniquely human emotions, we measured six N-UH emotions (pleasure, surprise, attraction, anger, disgust, fear) attributed to Uzbeks ( $\alpha=.61$ ). However, some of the primary emotions included in this measure overlap with those employed in the manipulation, therefore this measure should be considered as a partial manipulation check more than a completely independent measure for comparison with UH emotions. These terms were validated in Prati, Vasiljevic, Crisp and Rubini (2015). Emotional terms denoting negative and positive emotions were equally balanced across the measures of $\mathrm{N}-\mathrm{UH}$ and $\mathrm{UH}$ emotions. Further measures were the same as in Experiment 1: HN traits $(\alpha=.64)$, UH traits $(\alpha=.75)$ and feelings of prejudice towards Uzbeks $(\alpha=.85)$.

Measures not analyzed were: a six-item scale of perceived Uzbek entitativity, and free listings of traits and emotions characteristic of the Uzbeks. Additionally, participants were asked to write afterwards what they thought the study was about, and while most guessed that the study obviously was about group perception or prejudice, none correctly guessed our intent to manipulate the presentation of emotions. 


\section{Results}

Table 2 provides means, standard deviations and intercorrelations for all variables, and means comparing the mixed and same valence conditions.

\section{Human Emotions}

UH Emotions. In line with Experiment 1's results, we found that participants in mixed valence emotions conditions were more likely to attribute to Uzbeks the ability to express UH emotions compared to participants in the same valence emotions conditions, $t(77)=-2.63, p=$ $.010, d=.56$ (see Table 2). Nested effects of positive- vs. negative-first unmixed emotions, $t(37)=$ $0.56, p=.573, d=.17$, and of the mixed emotions conditions, $t(38)=-0.65, p=.518, d=.21$, were not significant.

N-UH Emotions. There was no significant difference between mixed and same valence conditions on attribution of N-UH emotions, $t(77)=-0.05, p=.957, d=.01$. This should not be surprising, as all conditions presented the Uzbeks as feeling four separate $\mathrm{N}-\mathrm{UH}$ emotions. Nested effects of positive- vs. negative-first unmixed emotions, $t(37)=0.08, p=.936, d=.029$, and of the different mixed emotions conditions, $t(38)=-0.04, p=.968, d=.02$, were not significant.

A 2 (emotional complexity: same, mixed valence emotions) $\times 2$ (emotions: UH, N-UH) mixed model ANOVA with repeated measures on the last factor was conducted on the two types of emotion scores. Results revealed a significant Emotional Complexity $\times$ Emotion interaction, $F(1$, 77) $=5.66, p=.020, \eta^{2}=.07$, showing that the two emotion types were affected in different ways by mixed vs. same emotional complexity. Main effects were not significant.

\section{Human Traits}

UH traits. Participants in mixed valence conditions attributed more UH traits to Uzbeks compared to participants in the same valence emotions conditions, $t(77)=-2.08, p=.041, d=.48$. 
Nested effects of positive- vs. negative-first unmixed emotions $t(37)=0.02, p=.987, d=.02$ and of the different mixed emotions conditions $t(38)=-0.87, p=.389, d=.27$ were not significant.

HN traits. As in Experiment 1, there was no significant difference between emotional complexity conditions on attribution of $\mathrm{HN}$ traits, $t(77)=0.87, p=.384, d=.20$. Nested effects of positive- vs. negative-first unmixed emotions $t(37)=0.03, p=.495, d=-.22$ and of the different mixed emotions conditions $t(38)=1.51, p=.138, d=.48$ were not significant.

A 2 (emotional complexity: same, mixed valence emotions) $\times 2$ (human traits: $U H, H N$ ) mixed model ANOVA with repeated measures on the last factor was conducted to compare the two types of human traits scores. Results revealed a significant human traits main effect $F(1,77)=$ 4.93, $p=.029, \eta^{2}=.06$ showing that $\mathrm{HN}$ traits were rated higher $(M=4.02, S D=0.07)$ than $\mathrm{UH}$ traits $(M=3.78, S D=0.07)$. This was qualified by a marginally significant Emotional Complexity $\times$ Human Traits interaction, $F(2,77)=3.81, p=.053, \eta^{2}=.05$, showing a trend toward the effect on UH traits being stronger than the effect on $\mathrm{HN}$ traits.

\section{Prejudice}

There was a significant difference between conditions in intergroup prejudice, $t(77)=2.73$, $p=.008, d=-.674$. As expected, Uzbeks described as expressing mixed emotions attracted reduced intergroup prejudice (greater liking) compared to the same-valence conditions. Nested effects of positive- vs. negative-first unmixed emotions showed a significant effect, $t(37)=-2.89, p$ $=.006, d=-.929$ indicating that Uzbeks described as expressing unmixed positive emotions first $(M$ $=3.29, S D=0.84$ ) elicited higher intergroup prejudice (lower liking) compared to the those expressing unmixed negative emotions first $(M=3.95, S D=0.55)$. No significant effect was found between different mixed emotions conditions $t(38)=-0.39, p=.694, d=-.122$.

\section{Mediation}


We again used the same bootstrapping procedure as in Study 1 to test the mediating role of UH emotions and UH traits in the relationship between manipulation of Uzbeks' emotion complexity and prejudice toward them (see Figure 2). Comparing indirect effects, UH emotions (B $=-.21, \mathrm{SE}=.11,95 \% \mathrm{Cl}=-.50$; to -.05$)$ rather than $\mathrm{UH}$ traits $(\mathrm{B}=-.04, \mathrm{SE}=.07,95 \% \mathrm{Cl}:-.23$ to .06$)$ again mediated emotional complexity effects on prejudice towards Uzbeks.

\section{Discussion}

Experiment 2 supported and extended Experiment 1's findings by showing that Uzbeks' expression of mixed valence vs. same valence emotions elicited higher attribution of UH but not NUH emotions to the target in question. This experiment also showed that the manipulation of emotional complexity reduced prejudice even toward a real and unfamiliar outgroup and this effect was explained by the attribution of UH emotions, but not by the attribution of UH traits.

\section{Experiment 3}

Experiment 3, conducted in Italy, built on the previous two experiments by using a more commonly known outgroup for majority Italian participants, namely Muslims. This experiment in a new setting also included some changes to the manipulation. First, the outgroup target emotions were situated with greater intergroup meaning, as a reaction to protest actions by other members of the outgroup target, for which both positive and negative emotions (e.g. anger) could signal solidarity with the protests. We also strengthened the manipulation by presenting the unmixed emotion conditions as emotions of the same valence (exclusively positive or negative between participants), rather than presenting them in matched pairs (only positive first and only negative after or vice versa) as in the previous two studies.

Because attribution of UH traits was not a mediator of the mixed emotion effect in either experiment, showing low reliability and weaker effects than emotions, we included a different non-emotional measure of infrahumanization. This was a direct and explicit measure of the 
association between outgroup, Muslims (vs. ingroup) and humans (vs. animals). Finally, we moved from a measure of attitudinal prejudice to a measure of intended behavioral prejudice in the form of social distance. This was possible because, unlike the imaginary or remote outgroups in the previous two studies, the Muslim group here was one belonging to Italian society, with which the participants could realistically choose to interact or not.

\section{Method}

\section{Participants and Research Design}

Seventy-one students (54 females and 17 males, $M_{\text {age }}=22.40, S D=3.07$ ) at an Italian university participated in the experiment on a voluntary basis. As in the previous experiments, the design crossed valence (positive vs. negative) and complexity (same vs. mixed) conditions. Sample size was intended to be generally similar to the previous two studies. All measures were translated into Italian.

\section{Procedure and Measures}

Participants were asked to read the following cover story on Muslims and then answer some questions on their impression about them. "An obscure slapstick film said to be entitled Innocence of Muslims or Life of Muhammed has been cited as the cause for riots at US diplomatic posts in Egypt and Libya. Many other fresh protests suddenly took place around the Muslim world over this amateur anti-Islam video produced in the US. The news of these upheavals about insult to the Prophet has suddenly spread widely and through the web people are trying to make sense of these events. During an interview about the current situation, a group of Muslims in Algeria expressed at the same time specific emotions." In the positive same valence emotions condition Muslims expressed "excitement and pleasure"; in the negative same valence condition they expressed "fear and anger". In one of 
the mixed valence emotions conditions they expressed "excitement and fear", in the other "anger and pleasure".

\section{Dependent Variables}

Human and animal metaphors. Drawing from Viki et al. (2006), participants completed a measure of relative outgroup dehumanization. They were presented with a list of 10 typical Muslim names listed on the left side of the page. On the right of the same page was a list of 20 words (10 human and 10 animal). These words were randomly ordered. Participants were instructed that, for each name on the left, they should pick a word that best characterizes it and draw a line to link the two. Participants were told that once they had chosen a word to be associated with a name, they could not choose that word again.

$\mathrm{UH}$ and $\mathrm{N}-\mathrm{UH}$ emotions. Furthermore, using the same measures as in Experiment 2, we asked participants to indicate to what extent they thought Muslims would be able to express N-UH $(\alpha=.90)$ and UH emotions $(\alpha=.89)$.

After completing demographic measures, at the end of the questionnaire, participants were presented a list of 10 Italian names to associate with the same list of 20 words already presented (relative ingroup dehumanization). This task was presented separately from the Muslim word association task, to avoid direct comparison between responses.

Social distance. Participants also completed seven items drawing from the social distance scale by Bogardus (1933), indicating how willing they would be to engage in activities or relationships, varying in terms of closeness with a Muslim person (e.g. renting the person a room in your house, have him/her as a colleague at work). The 7 items were reversed to indicate higher social distance with higher scores. The internal consistency of the scale items was high (Cronbach's alpha .91). 
As before, no participant guessed the purpose of varying the emotions when asked to describe the study's intent.

\section{Results}

Table 3 provides means, standard deviations and intercorrelations for all variables.

\section{UH and N-UH Emotions}

UH emotions. Participants in mixed valence emotions conditions were marginally more likely to attribute to Muslim targets the ability to express UH emotions compared to participants in same-valence emotions conditions, $t(69)=-1.94, p=.056, d=.46$. Nested effects of positive vs. negative unmixed emotions, $t(29)=-0.06, p=.956, d=.03$ and mixed emotions conditions, $t(38)=$ $0.24, p=.815, d=.08$, were not significant.

$\mathrm{N}$-UH emotions. No significant difference in the attribution of $\mathrm{N}-\mathrm{UH}$ emotions was found between participants who saw mixed emotions and those who saw same-valence emotions, $t(69)$ $=-0.11, p=.915, d=.025$. Nested effects of positive vs. negative unmixed emotions $t(29)=-0.57, p$ $=.576, d=.202$ and mixed emotions conditions $t(38)=0.43, p=.053, d=.641$ were not significant.

A 2 (emotional complexity: same, mixed valence emotions) $\times 2$ (emotions: $\mathrm{N}-\mathrm{UH}, \mathrm{UH}$ ) mixed model ANOVA with repeated measures on the last factor was conducted on two types of emotions scores. Results revealed a marginal main effect of emotion complexity, $F(1,69)=3.28, p$ $=.075, \eta^{2}=.045$ and no effect of emotions $F(1,69)=0.04, p=.834, \eta^{2}=.000$, nor interaction, $F$ $(69)=1.49, p=.225, \eta^{2}=.021$.

\section{Human vs. Animal Metaphors}

Total scores for the number of human-related words attributed to Muslims and to the Italians were computed for each participant (human and animal words always added to ten, so analyzing animal words separately would be redundant). We then conducted two mixed, 
Emotional Complexity $x$ Target Nationality ANOVAs to check for significant differences in the association of the outgroup (Muslims) and the ingroup (Italians) with human-related words.

The analysis revealed a main effect of emotional complexity manipulation, $F(1,69)=5.06$, $p=.028, \eta^{2}=.07$, and a main effect of target nationality, $F(1,69)=76.11, p=.001, \eta^{2}=.52$ (see Table 3). These effects were qualified by a significant two-way interaction, $F(1,69)=4.11, p=$ $.047, \eta^{2}=.06$. Simple effect analyses indicated that participants in the mixed emotion condition chose human-related words for the Muslims (outgroup) to a higher extent than those in the same emotion condition $\left.F(1,69)=7.56, p=.008, \eta^{2}=.10\right)$ but this effect was not present for the Italian ingroup target (same $M=8.68, S D=1.85 ;$ mixed $M=8.70, S D=1.45), F(1,69)=0.00, p=.954, \eta^{2}=$ .000 . Nested effects of positive vs. negative unmixed emotions, $t(29)=-1.48, p=.150, d=-.54$, and mixed emotion order, $t(38)=0.71, p=.479, d=.226$, on human-related words attributed to Muslims were not significant. Similarly, nested effects of positive vs. negative unmixed emotions, $t(29)=-1.00, p=.325, d=-.36$, and mixed emotions order, $t(38)=1.16, p=.25, d=.37$ on humanrelated words attributed to Italians were not significant.

\section{Social Distance}

As expected, mixed valence emotions conditions enhanced participants' willingness to reduce social distance and engage in contact with Muslims compared to same valence emotions conditions $t(69)=2.33, p=.022, d=.56$. Nested effects of positive vs. negative unmixed emotions, $t(29)=-.11, p=.91, d=-.04$, and of the different mixed emotions conditions, $t(38)=1.12, p=.27$, $d=.36$, were not significant.

\section{Mediation}

We again tested the mediating role of UH emotions and human-related words attributed to Muslims on the relationship between emotional complexity manipulation and social distance (see Figure 3). Comparing indirect effects, $\mathrm{UH}$ emotions $(\mathrm{B}=-.36, \mathrm{SE}=.11,95 \% \mathrm{Cl}=-.59$ to -.14 ) 
rather than human-related words $(B=.06, \mathrm{SE}=.07,95 \% \mathrm{Cl}=-.09$ to .21$)$ mediated emotional complexity effects on social distance.

\section{Meta-Analysis}

In three studies, we have shown fairly consistent evidence that describing mixed emotions among members of another group improves the ascription of humanness to them in terms of perceived ability to express UH emotions, uniquely human traits and descriptive words, and reduced prejudice and social distance.

In Studies 1 and 2 we found a significant effect of our manipulation on perceived UH emotions, whereas in Study 3 the result was only marginally significant and not different from $\mathrm{N}$ UH emotions, even if results were in the same direction. Yet, it might still be that in the aggregate, multiple significant and non-significant effects could accumulate to show overall evidence of a link between perception of others' emotional complexity and attribution of UH emotions (Goh, Hall \& Rosenthal, 2016).

To test this possibility, we meta-analytically combined the effect sizes for the mixed/same emotion manipulation on UH emotion attribution reported in Studies 1, 2 and 3 $(\mathrm{N}=217)$, weighting each effect size $d$ by the inverse variance method (using SPSS macros supplied by Wilson, 2005). This analysis yielded an overall effect size $\mathrm{d}=.52,95 \% \mathrm{Cl}: .26$ to .81 and an overall $p<.001$, showing strong aggregate evidence for the effect.

Applying this method to each of the other outcomes measured in more than one study, we found that:

$\mathrm{N}$-UH emotions (Experiments 2 and 3), were not affected by the manipulation, $d=.02$, $95 \% \mathrm{Cl}:-.30$ to $.34, \mathrm{p}=.91$.

UH traits (Experiments 1 and 2) were more strongly attributed in mixed vs. same emotion conditions, $d=.60,95 \% \mathrm{Cl} . .27$ to $.94, \mathrm{p}<.001$. 
$\mathrm{N}-\mathrm{UH}$ traits (Experiment 1 and 2 ) were not affected by the manipulation, $\mathrm{d}=.22,95 \% \mathrm{Cl}$ : .10 to $.53, p=.18$.

Prejudice (including social distance in Experiment 3) was more strongly attributed in mixed vs. same emotion conditions, $d=.73,95 \% \mathrm{Cl}$ : .45 to $1.01, \mathrm{p}<.001$.

\section{General Discussion}

In the present research, we provided evidence that mixed valence emotions experienced by outgroup members can reduce dehumanization of them. Specifically, Experiment 1 showed that perceiving fictitious group members' expression of mixed vs. same valence emotions increase their humanization, in terms of attribution of uniquely human (but not human nature) traits and the ability to express UH emotions to them. Moreover, the manipulation reduced prejudice towards the group and this effect was explained by increased UH emotions. Experiment 2 confirmed Experiment 1's results by using a real outgroup. We found that perceiving Uzbeks' mixed vs. same valence emotions enhanced their humanization, in terms of the ability to express UH emotions which in turns explained reduced prejudice towards them, while UH traits were also affected but not as conclusively implicated in prejudice reduction. Experiment 3 extended the previous experiments by showing that the manipulation of emotional complexity of known and disliked outgroup members (Muslims) promoted their humanization, in terms of UH emotions and explicit associations with the human category, and also reduced social distance from them. Moreover, mediation analyses showed that uniquely human emotions, rather than human-related words, could explain the effect of the mixed-emotion manipulation on reducing social distance.

\section{Implications for theory and research on cognitive complexity}


Our research supports and extends previous findings concerning the effectiveness of cognitive complexity in promoting intergroup tolerance (Linville, 1982). Social integration and openness to change are predicted by the perception of the complexity of the self in terms of individual's subjective representation of the interrelationships among his or her multiple group identities (Roccas \& Brewer, 2002). Similarly, increasing complexity of others through multiple and counter-stereotypical categorization can reduce dehumanization of them (Albarello \& Rubini, 2012; Prati, Crisp, \& Rubini, 2015; Prati, Crisp, Meleady \& Rubini, 2016) and enhance positive behavioral intentions (Prati, Crisp, Pratto \& Rubini, 2016; Prati, Menegatti \& Rubini, 2015).

In this vein, we showed that social inclusion in the human group of outgroup targets is increased by increasing the emotional complexity attributed to them, through the description of feeling simultaneously mixed compared to same valence emotions. Importantly, this evidence was obtained by manipulating the presentation of the same quantity of $\mathrm{N}-\mathrm{UH}$ emotions that are not exclusively associated with human beings. Thus, the humanization effect was driven by the combination, rather than type or quantity, of emotions perceived.

\section{Implications for theory and research on dehumanization}

Across the studies, results generally affirm that this strategy on emotional complexity affects especially human uniqueness, the distinction of human beings from animals (Haslam, 2006), implying that this new strategy to reduce dehumanization may be applied to animalized group targets (i.e., artists; Loughnan \& Haslam, 2007), but would not work as well for groups seen in terms of other metaphors (i.e., business people; Loughnan and Haslam, 2007). It should also be noted that our measures of human traits, although based on already-published instruments, suffered from low reliability, which may have limited their effectiveness as mediators. The null results for mentalization in Study 1 likewise may have been due to the scale's low reliability. 
Another question that arises is whether the results of our manipulations can best be described as an increase in humanization or a decrease in dehumanization There is suggestive evidence in Experiment 2, in which presenting mixed emotional experience brings ratings of UH emotions to a value nearly identical to ratings for $\mathrm{N}-\mathrm{UH}$ emotions, while in Experiment $3 \mathrm{UH}$ emotion ratings actually exceed N-UH emotions when valence is mixed (see Tables 2, 3). However, Experiment 3 contains the most valid evidence on this point because it directly compares ingroup and outgroup members on ratings of human-related aspects (Table 3). This reveals a sad state of affairs; when expressing unmixed emotions, Muslims are rated nearly equal on human and animal words. Mixed emotions move these ratings apart, but Muslims still are not granted the same amount of relative humanity as Italians are, who are rated near the maximum on human words and minimum on animal. On this direct measure, the answer is clear: mixed emotions can reduce but not completely eliminate relative dehumanization.

Moreover, we consistently showed that attribution of UH emotions but not UH traits explains the effects of emotional complexity. This evidence highlights that this strategy enhances social inclusion through the recognition of the uniquely human affective side of others. Interestingly, among the different humanization measures that we used, only UH emotions explain the effect of emotional complexity on prejudice. In contrast, UH traits and UH words did not mediate the effect of emotional complexity, because these measures were not independently related to prejudice. The final step in each mediation clearly shows that, when these measures are pitted against each other, UH emotions explain variance in prejudice that UH traits or UH words do not. It could also be that the UH emotion measure, concerning the extent to which participants think the target group may experience various emotions, is a more indirect measure of prejudice, and thus captures more true feelings compared to the measures involving the attribution of UH traits and words, which more directly present concepts with inherent and evident value. 
One limitation of this research is that it consists only of vignette-based studies. Further research should test the effectiveness of emotional complexity in a real context. However, this imagination-based strategy, similar to others such as imagined contact (Miles \& Crisp, 2014) or multiple categorization (Crisp \& Hewstone, 2007) can be used as a preparation to increase positive attitudes and hence (as our Study 3 social distance measure showed) willingness to engage in real intergroup contact. Valence differentiates emotions more strongly than other features (Larsen \& McGraw, 2014), for example, the combination of anger and joy is more cognitive depleting and difficult to evaluate compared to the combination of anger and sadness. In this vein, we employed different valence emotion as the strongest example of mixed emotions and emotional complexity. Future research could possibly get even stronger effects by contrasting multiple with single emotions as another way in which emotional complexity can be manipulated, although with the confound of number and possible intensity of inferred emotion. The present research chose to eliminate that confound by studying the effect of structural emotion complexity independently of mere number of emotions.

\section{Note on research practice and statistical power}

The studies we report here might be criticized by present-day standards for having low power to detect their effect. First of all, although each experiment is a $2 \times 2$ design, the main comparison of theoretical interest is a two-level effect with at least 30 participants in each cell. The key effects of interest, post hoc, appear to be medium to large sized (the meta-analysis showing them to be in the $d=.52$ to $d=.73$ range), and our studies had power ranging from .78 to .84 to detect a $d=.60$ effect. Moreover, these studies are the only ones either author has conducted to test the mixed emotions hypothesis, and in all three studies we reported all manipulations and all measures, while data collection was stopped independently of the results. In 
sum, we are confident that these significant results represent a substantial level of evidence in favor of our hypotheses.

\section{Conclusion}

To conclude, the present research illustrates a new strategy to reduce one of the most heinous forms of discrimination: dehumanization. Emphasizing the mixed-valence emotional experiences of outgroups might be particularly effective because it does not require people to suspend their disbelief that an outgroup might feel secondary emotions. These findings add further evidence to the more general theory that perceiving cognitive complexity in an outgroup helps in improving intergroup relations (Crisp \& Turner, 2011). Encouraging groups to see and communicate each other mixed emotional experiences may have potential to improve the social harmony of today's multicultural societies. 


\section{References}

Albarello, F., \& Rubini, M. (2012). Reducing dehumanization outcomes towards Blacks: The role of multiple categorization and of human identity. European Journal of Social Psychology, 42, 801-938.

Bar-Tal, D. (1990). Causes and consequences of delegitimization: Models of conflict and ethnocentrism. Journal of Social Issues, 46, 65-81.

Bogardus, E. S. (1933). A social distance scale. Sociology and Social Research, 17, 265-271.

Castano, E., \& Giner-Sorolla, R. (2006). Not quite human: Infra-humanization as a response to collective responsibility for intergroup killing. Journal of Personality and Social Psychology, 90, 804-818.

Čehajić, S., Brown, R., \& González, R. (2009). What do I care? Perceived ingroup responsibility and dehumanization as predictors of empathy felt for the victim group. Group Processes \& Intergroup Relations, 12, 715-729.

Chisango, T. (2012). Investigating the role of denial of cognition, capacity for morality and perception of child-likeness in infrahumanization. Journal of Social Sciences, 30, 71-81.

Crisp, R. J., \& Hewstone, M. (2007). Multiple social categorization. Advances in Experimental Social Psychology, 39, 163-254.

Crisp, R. J., \& Turner, R. N. (2011). Cognitive adaptation to the experience of social and cultural diversity. Psychological Bulletin, 137, 242-266. 
Cuddy, A. J., Rock, M. S., \& Norton, M. I. (2007). Aid in the aftermath of Hurricane Katrina: Inferences of secondary emotions and intergroup helping. Group Processes \& Intergroup Relations, $10,107-118$.

Demoulin, S., Leyens, J. P., Paladino, M. P., Rodriguez-Torres, R., Rodriguez-Perez, A., \& Dovidio, J. F. (2004). Dimensions of "uniquely" and "non-uniquely" human emotions. Cognition and Emotion, 18, 71-96.

Ersner-Hershfield, H., Mikels, J. A., Sullivan, S. J., \& Carstensen, L. L. (2008). Poignancy: Mixed emotional experience in the face of meaningful endings. Journal of Personality and Social Psychology, 94, 158-167.

Fontaine, J. R. J., Scherer, K. R., Roesch, E. B., \& Ellsworth, P. C. (2007). The world of emotions is not two-dimensional. Psychological Science, 18, 1050-1057.

Goh, J. X., Hall, J. A., \& Rosenthal, R. (2016). Mini meta-analysis of your own studies: Some arguments on why and a primer on how. Social and Personality Psychology Compass, 10(10), 535-549.

Greitemeyer, T., \& McLatchie, N. (2011). Denying humanness to others a newly discovered mechanism by which violent video games increase aggressive behavior. Psychological Science, 20, 1-7.

Haslam, N., \& Loughnan, S. (2014). Dehumanization and infrahumanization. Annual Review of Psychology, 65, 399-423. 
Hershfield, H. E., Scheibe, S., Sims, T. L., \& Carstensen, L. L. (2013). When feeling bad can be good mixed emotions benefit physical health across adulthood. Social Psychological and Personality Science, 4, 54-61.

Kelman, H. C. (1973). Violence without moral restraint: Reflections on the dehumanization of victims and victimizers. Journal of Social Issues, 23, 25-61.

Larsen, J. T., To, Y. M., \& Fireman, G. (2007). Children's understanding and experience of mixed emotions. Psychological Science, 18, 186-191.

Larsen, J. T., \& McGraw, A. P. (2014). The Case for Mixed Emotions. Social and Personality Psychology Compass, 8, 263-274.

Leyens, J. P., Paladino, M. P., Rodriguez, R. T., Vaes, J., Demoulin, S., Rodriguez, A. P., et al. (2000). The emotional side of prejudice: The role of secondary emotions. Personality and Social Psychology Review, 4, 186-197.

Leyens, J. P., Rodriguez-Perez, A., Rodriguez-Torres, R., Gaunt, R., Paladino, M. P., Vaes, J., \& Demoulin, S. (2001). Psychological essentialism and the differential attribution of uniquely human emotions to ingroups and outgroups. European Journal of Social Psychology, 31, 395-411.

Linville, P. W. (1982). Affective consequences of complexity regarding the self and others. In M. S. Clark \& S. T. Fiske (Eds.), Affect and cognition: The Seventeenth Annual Carnegie Symposium on Cognition (pp. 79-109). Hillsdale, NJ: Erlbaum.

Loughnan, S., Haslam, N., \& Kashima, Y. (2009). Understanding the relationship between attribute-based and metaphor-based dehumanization. Group Processes \& Intergroup Relations, 12, 747-762. 
Loughnan, S., \& Haslam, N. (2007). Animals and androids implicit associations between social categories and nonhumans. Psychological Science, 18, 116-121.

Miles, E., \& Crisp, R. J. (2014). A meta-analytic test of the imagined contact hypothesis. Group Processes \& Intergroup Relations, 17, 3-26.

Opotow, S. (1990). Moral exclusion and injustice: An introduction. Journal of Social Issues, 46, 120.

Prati, F., Crisp, J. R., Meleady, R., \& Rubini, M. (2016). Humanizing outgroups through multiple categorization: The roles of individuation and threat. Personality and Social Psychology Bulletin, 42, 526-539.

Prati, F., Crisp, R. J., Pratto, F., \& Rubini, M. (2016). Encouraging majority support for immigrant access to health services: Multiple categorization and social identity complexity as antecedents of health equality. Group Processes \& Intergroup Relations, 19, 426-438.

Prati, F., Crisp, J. R., \& Rubini, M. (2015). Counter-stereotypes reduce emotional intergroup bias by eliciting surprise in the face of unexpected category combinations. Journal of Experimental Social Psychology, 61, 31-43.

Prati, F., Menegatti, M., e Rubini, M. (2015). The beneficial role of multiple categorization and intergroup contact in reducing linguistic out-group derogation. Journal of Language and Social Psychology, 34, 475-500.

Prati, F., Vasiljevic, M., Crisp, J. R., \& Rubini, M. (2015). Some extended psychological benefits of challenging social stereotypes: Decreased dehumanization and a reduced reliance on heuristic thinking. Group Processes \& Intergroup Relations, 18, 801-816. 
Preacher, K. J., \& Hayes, A. F. (2008). Asymptotic and re-sampling strategies for assessing and comparing indirect effects in multiple mediator models. Behavior Research Methods, 40, 879-891.

Roccas, S., \& Brewer, M. B. (2002). Social identity complexity. Personality and Social Psychology Review, 6, 88-106.

Romney, A. K., Moore, C. C., \& Rusch, C. D. (1997). Cultural universals: Measuring the semantic structure of emotion terms in English and Japanese. Proceedings of the National Academy of Sciences, 94, 5489-5494.

Shaver, P., Schwartz, J., Kirson, D., \& O'connor, C. (1987). Emotion knowledge: Further exploration of a prototype approach. Journal of Personality and Social Psychology, 52, 1061-1086.

Simmons, J. P., Nelson, L. D., \& Simonsohn, U. (2011). False-positive psychology: Undisclosed flexibility in data collection and analysis allows presenting anything as significant. Psychological Science, 22, 1359-1366.

Simmons, J. P., Nelson, L. D., \& Simonsohn, U. (2017). False-positive citations. In press, Perspectives on Psychological Science. Retrieved from https://papers.ssrn.com/sol3/Papers.cfm?abstract_id=2916240.

Staub, E. (1989). The roots of evil: Psychological and cultural origins of genocide and other group violence. New York: Cambridge University Press. 
Vaes, J., Leyens, J. P., Paladino, M.P., \& Miranda, M. P. (2012). We are human, they are not:

Driving forces behind outgroup dehumanization and the humanization of the ingroup. European Review of Social Psychology, 23, 64-106.

Viki, G. T., Winchester, L., Titshall, L., Chisango, T., Pina, A., \& Russell, R. (2006). Beyond secondary emotions: The infrahumanization of outgroups using human-related and animal-related words. Social Cognition, 24, 753-775.

Wilson, D. B. (2005). Meta-analysis macros for SAS, SPSS, and Stata. Retrieved November 6, 2015 from http://mason.gmu.edu/ dwilsonb/ma.html

Wright, S. C., Aron, A., McLaughlin-Volpe, T., \& Ropp, S. A. (1997). The extended contact effect: Knowledge of cross-group friendships and prejudice. Journal of Personality and Social Psychology, 73, 73-90. 


\section{Footnotes}

${ }^{1}$ Given that in Study 2 we considered not only UH but also N-UH emotions, we employed only six of the eight UH emotions used in Study 1 to shorten the questionnaire, removing "pride" and "regret". 
Table 1. Scale Means, Standard Deviations, and Correlations (Experiment 1).

\begin{tabular}{|c|c|c|c|c|c|c|}
\hline & $\begin{array}{c}\text { Same valence } \\
\text { emotions } \\
M(S D)\end{array}$ & $\begin{array}{c}\text { Mixed valence } \\
\text { emotions } \\
M(S D)\end{array}$ & 1. & 2. & 3. & 4. \\
\hline $\begin{array}{l}\text { 1. UH } \\
\text { emotions }\end{array}$ & $3.81(.58)$ & $4.13(.62)$ & -- & $.54 * *$ & $.60 * *$ & $-.40 * *$ \\
\hline 2. UH traits & $3.75(.64)$ & $4.21(.58)$ & & -- & $.60^{* *}$ & $-.34^{* *}$ \\
\hline 3. UN traits & $3.88(.46)$ & $4.03(.81)$ & & & -- & -.14 \\
\hline 4. Prejudice & $3.56(.84)$ & $2.79(.73)$ & & & & -- \\
\hline
\end{tabular}

Note. ${ }^{*} p<.05 ;{ }^{* *} p<.01$. 
Table 2. Scale Means, Standard Deviations, and Correlations (Experiment 2).

\begin{tabular}{|c|c|c|c|c|c|c|c|}
\hline & $\begin{array}{c}\text { Same valence } \\
\text { emotions }\end{array}$ & $\begin{array}{c}\text { Mixed } \\
\text { valence } \\
\text { emotions }\end{array}$ & & & & & \\
\hline & $M(S D)$ & $M(S D)$ & 1. & 2. & 3. & 4. & 5. \\
\hline 1. UH emotions & $3.49(.74)$ & $3.94(.76)$ & -- & $.40 * *$ & $.77^{* *}$ & $-.26^{*}$ & $-.51^{* *}$ \\
\hline $\begin{array}{l}\text { 2. N-UH } \\
\text { emotions }\end{array}$ & $3.90(.67)$ & 3.89 (.95) & & -- & $.45^{* *}$ & $-.32 * *$ & -.20 \\
\hline 3. UH traits & $3.62(.50)$ & $3.93(.76)$ & & & -- & -.17 & $-.41^{* *}$ \\
\hline 4. $\mathrm{HN}$ traits & 4.09 (.59) & $3.96(.68)$ & & & & -- & .18 \\
\hline 5. Prejudice & $3.65(.78)$ & $3.03(1.04)$ & & & & & -- \\
\hline
\end{tabular}

Note. ${ }^{*} p<.05 ;{ }^{* *} p<.01$. 
Table 3. Scale Means, Standard Deviations, and Correlations (Experiment 3).

\begin{tabular}{|c|c|c|c|c|c|c|c|c|c|}
\hline & $\begin{array}{c}\text { Same valence } \\
\text { emotions }\end{array}$ & $\begin{array}{c}\text { Mixed } \\
\text { valence } \\
\text { emotions }\end{array}$ & & & & & & & \\
\hline & $M(S D)$ & $M(S D)$ & 1 & 2. & 3. & 4. & 5. & 6. & 7. \\
\hline $\begin{array}{l}\text { 1. Animal } \\
\text { words to } \\
\text { Muslims }\end{array}$ & $4.77(2.07)$ & $3.55(1.93)$ & - & $-1.00 * *$ & -.04 & .04 & .08 & -.03 & -.04 \\
\hline $\begin{array}{l}\text { 2. Human } \\
\text { words to } \\
\text { Muslims }\end{array}$ & $5.20(2.00)$ & $6.50(1.96)$ & & -- & .06 & -.06 & -.12 & .14 & -.02 \\
\hline $\begin{array}{l}\text { 3. Animal } \\
\text { words to } \\
\text { Italians }\end{array}$ & $1.32(1.85)$ & $1.30(1.45)$ & & & -- & $-1.00 * *$ & .21 & $-.34 * *$ & .05 \\
\hline $\begin{array}{l}\text { 4. Human } \\
\text { words to } \\
\text { Italians }\end{array}$ & $8.68(1.85)$ & $8.70(1.45)$ & & & & -- & -.21 & $.34 * *$ & -.06 \\
\hline $\begin{array}{l}\text { 5. N_UH } \\
\text { emotions }\end{array}$ & 3.75 (1.07) & $3.78(1.27)$ & & & & & -- & $-.28^{*}$ & $-.27^{*}$ \\
\hline $\begin{array}{l}\text { 6. UH } \\
\text { emotions }\end{array}$ & 3.05 (1.57) & $4.15(1.14)$ & & & & & & -- & $-.41^{* *}$ \\
\hline $\begin{array}{l}\text { 7. Social } \\
\text { distance }\end{array}$ & $3.58(1.29)$ & $2.84(1.35)$ & & & & & & & -- \\
\hline
\end{tabular}

Note. ${ }^{*} p<.05 ;{ }^{* *} p<.01$. 
Figure 1: The mediating role of $\mathrm{UH}$ emotions and traits in the relationship between manipulation of creatures' emotion complexity and prejudice toward them (Experiment 1 ).

Note: ${ }^{*} p<.01,{ }^{* *} p<.05$

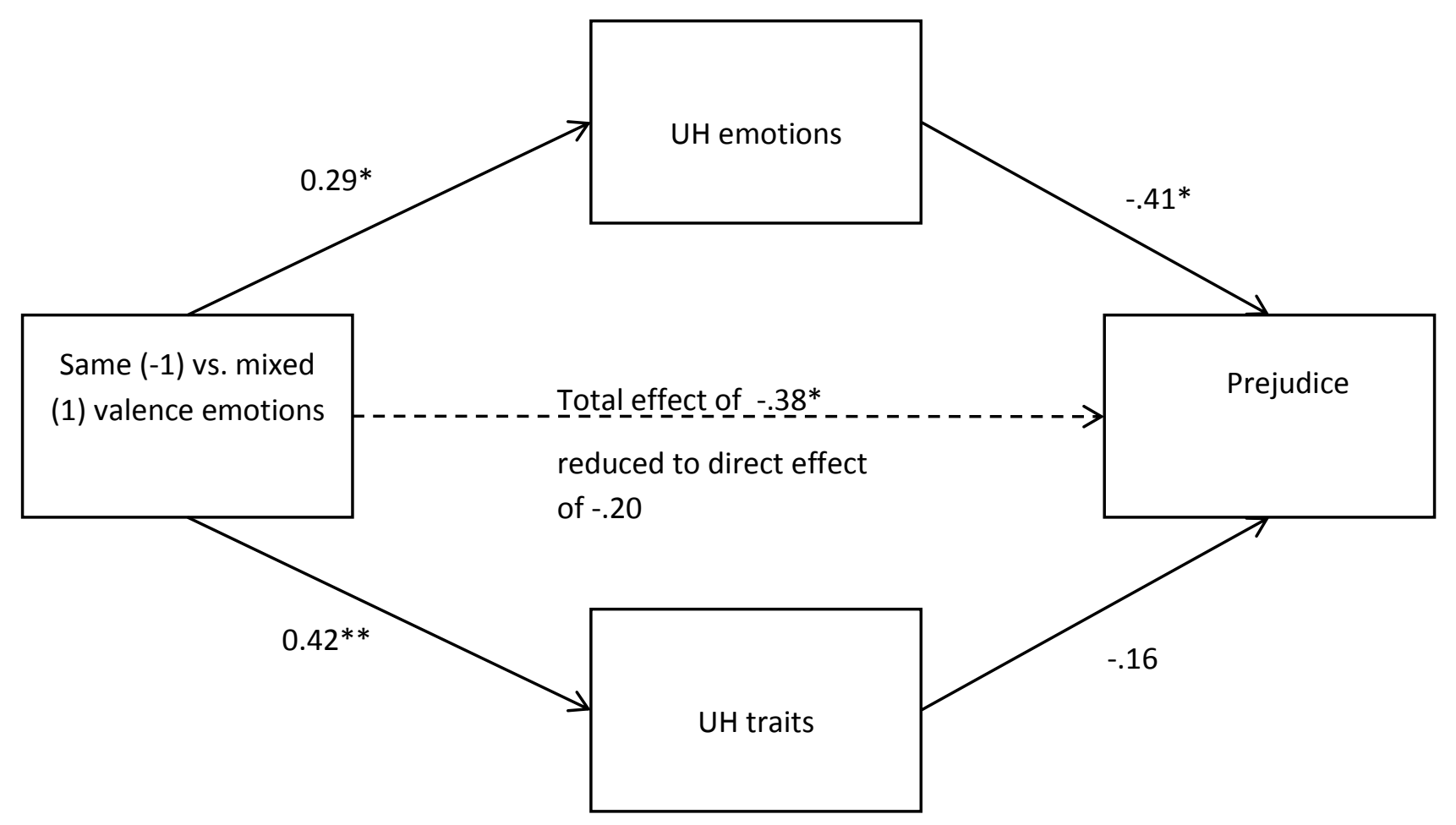

Adj $R^{2}=.239, F(3,62)=6.502, p=.007$ 
Figure 2: The mediating role of UH emotions and UH traits in the relationship between manipulation of creatures' emotion complexity and prejudice toward them (Experiment 2).

Note: ${ }^{*} p<.01,{ }^{* *} p<.05$

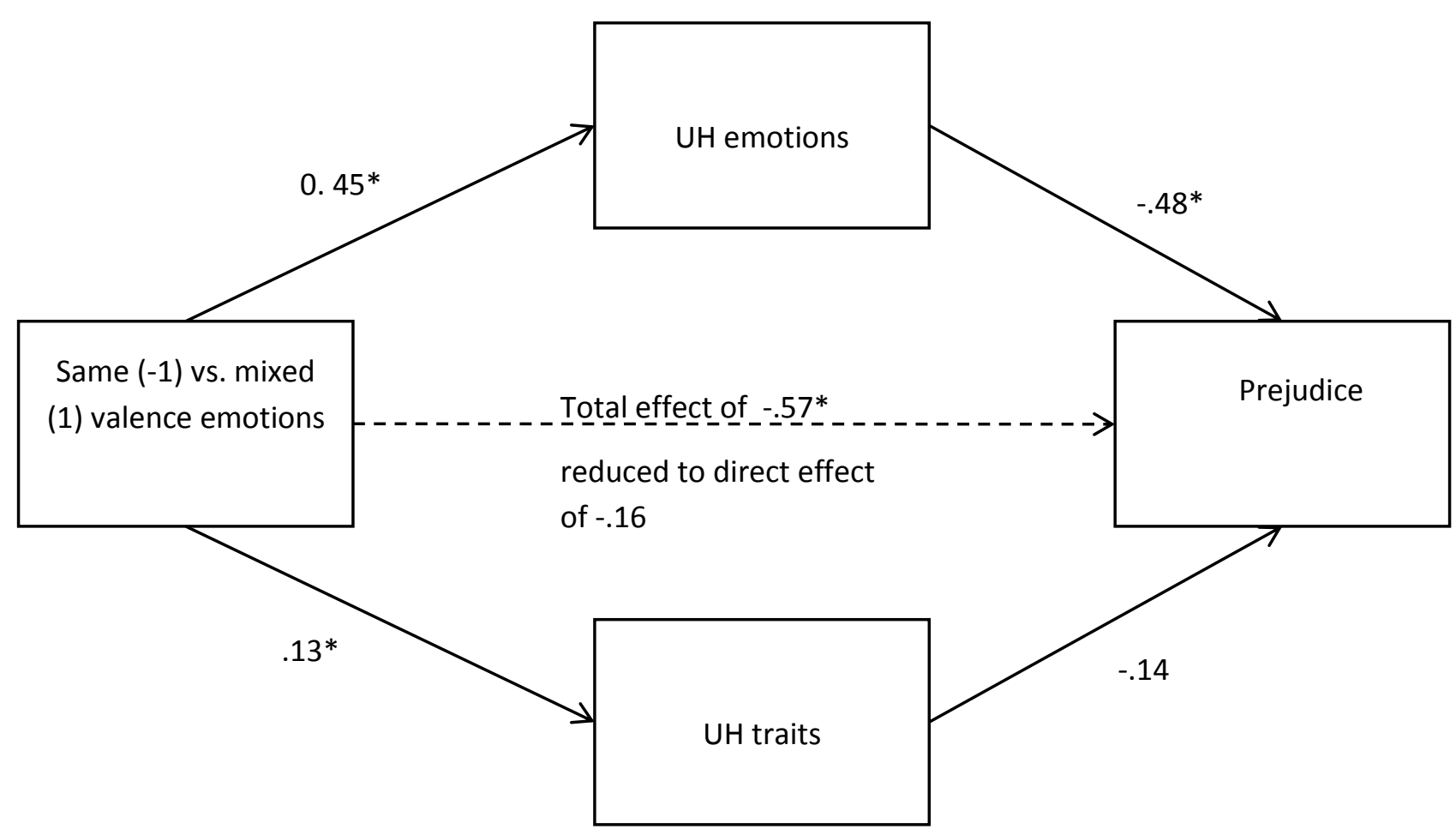

$\operatorname{Adj} R^{2}=.288, F(3,78)=10.120, p=.001$ 
Figure 3: Simple mediation test of the relationship between Muslims' emotion valence combination and intergroup social distance through attribution of UH emotions and humanrelated words to Muslims (Experiment 3).

Note: ${ }^{*} p<.01,{ }^{* *} p<.05$.

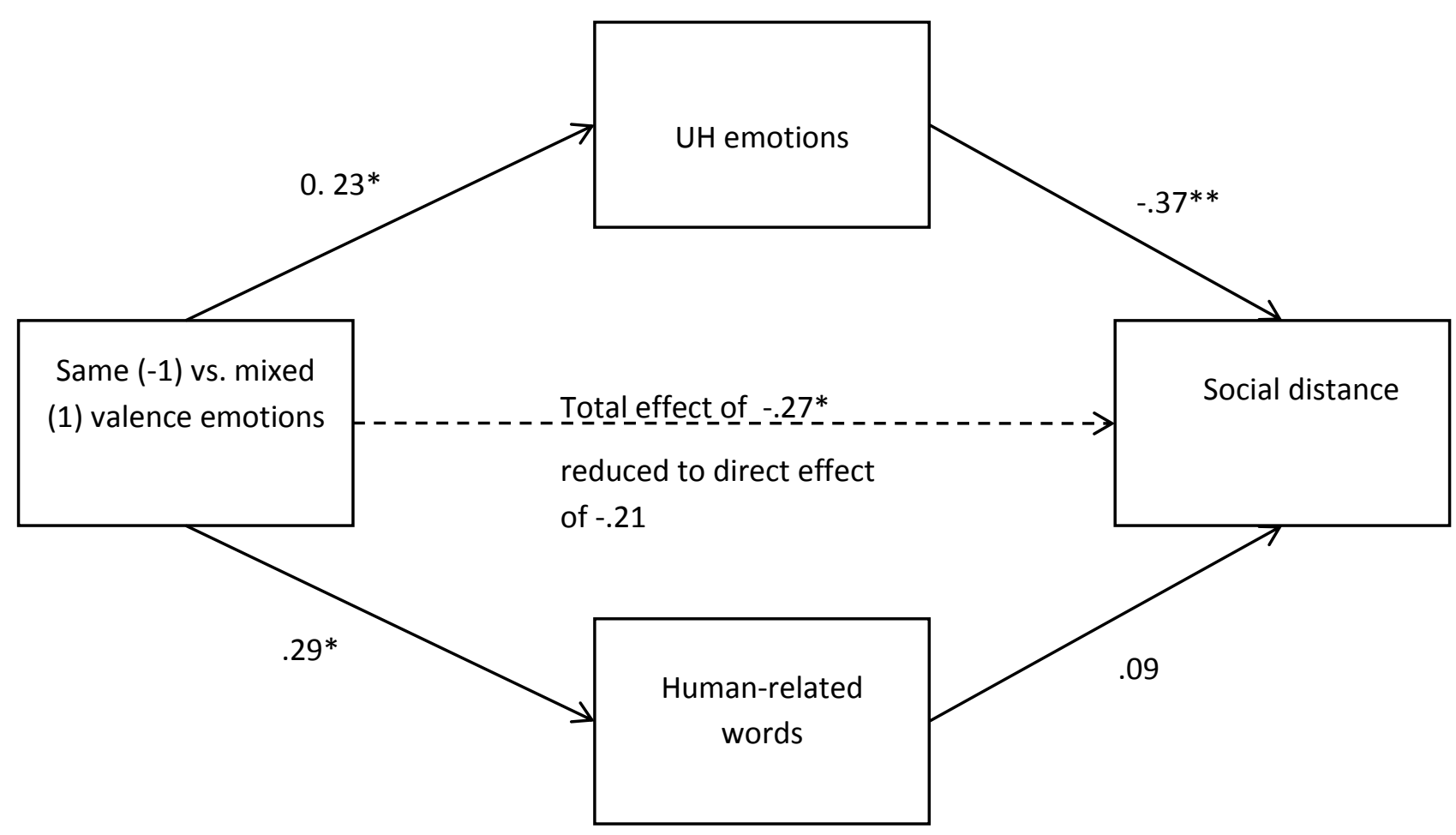

Adj $R^{2}=.171, F(3,70)=5.814, p=.001$ 